By: J. Scott Glass and James M. Benshoff

Glass, J. S., \& Benshoff, J. M. (1999). PARS: A processing model for beginning group leaders. Journal for Specialists in Group Work, 24, 15-26.

Made available courtesy of Taylor and Francis: http://www.tandf.co.uk/journals/titles/01933922.asp

****Note: Figures may be missing from this format of the document

\begin{abstract}
:
Group leaders often make extensive use of exercises and activities as part of the group counseling process. Experienced group leaders understand the critical importance of processing experiences with group members to help them reflect on, understand, and apply what has been learned to their lives outside the group. However, the basic skills required to process these experiences have been neglected both in the literature and in training for group leaders. This article presents the PARS model (focusing on Processing: Activity, Relationships, Self), a model for processing group activities that can be helpful in training beginning group leaders and that can provide a "road map" for group processing that can benefit even experienced group leaders.
\end{abstract}

\title{
Article:
}

Group work is widely used as an approach to counseling. Corey and Corey (1997) recognized the importance of groups, stating, "Groups are the treatment of choice, not a second rate approach to helping people change" (p. 5). In groups, members often participate in a variety of activities and experiences with the goal of gaining greater understanding of their personal issues. Experiential learning activities often are used to teach complex principles through the use of organized experiences (Dutton \& Stumpf, 1991; Thatcher, 1990) and frequently are used in the group counseling process. Because of their critical role in group counseling, much attention has been focused on teaching these activities to beginning group leaders. Many books of group exercises are available; yet, the basic skills required to process both structured and unstructured group experiences have been neglected (Kees \& Jacobs, 1990). Although group leadership is viewed as an art rather than a science, we also believe that the basic skills required to process group experiences effectively can be taught to group leaders, much the same as Ivey (1994), Egan (1994), and others have developed models for teaching basic helping skills.

In group counseling, processing refers to helping group members identify and examine what happened in the group and their individual experiences of the event, as well as how the event occurred and how different members responded to it. Processing activities and events in the group helps group members better understand their experiences in the group and relate these to their personal lives. The importance of this processing component for increasing individual learning and group productivity has been emphasized by researchers (Dishon \& O'Leary, 1984; Johnson \& Johnson, 1987; Johnson, Johnson, \& Holubec, 1986). Yager, Johnson, Johnson, and Snider (1986) investigated the effect on group productivity and individual achievement of cooperative learning groups with processing, those without processing, and those in which students worked on an individual basis only. They found that groups with processing accomplished the highest levels of daily achievement, problem- solving success, and long-term retention of relevant information. These findings support our contention that group activities and exercises must be followed by effective processing to have maximum impact on group members. However, it is important to acknowledge that group processing skills also require the facilitator to have the necessary understanding of group dynamics to be able to apply them meaningfully with groups.

Johnson, Johnson, Stanne, and Garibaldi (1990) found evidence that group processing increased members' individual achievement and group productivity. Sarason and Potter (as cited in Johnson et al., 1990) suggested that one possible explanation for this finding is that group processing increased members' self-efficacy by directing attention toward skillful cooperative behavior and by reducing personal inhibitions such as self-doubt. 
Without effective processing skills, group leaders may be putting their clients through activities without helping them realize the relation between what they do in the group setting and their everyday lives. Regardless of the population involved, successful facilitation involves more than simply engaging a group of people in a variety of exercises.

Beginning group facilitators often emphasize the activities themselves rather than the processing phase. Jacobs, Harvill, and Masson (1988) described the processing component as the most important phase of group work. Group activities should be designed with specific goals in mind, in the hope that what is learned through these activities then will transfer back into participants' interpersonal lives in some way. Processing of activities becomes the "bridge" from exercise to insight, from experience to behavior change. However, without proper leadership from the group facilitator, the learning that is intended to take place through the exercise may be lost on the group members, thereby minimizing the impact of the exercises.

Kees and Jacobs (1990) noted that there are few guidelines for processing the activity after it has been completed. Effective processing with groups involves skills in helping members process the thoughts, feelings, and reactions associated with a particular exercise in the context of the experience shared by all group members. This ability to facilitate group members' reflections on the exercise and relate what has been learned to their own lives and goals is what helps to make group work effective.

The purpose of this article is to outline a model for thinking about processing with group members following an exercise, structured activity, or other shared experience within the group. This type of processing is necessary for all group work, regardless of the participants involved, and is a critical component of the learning that takes place through the group experience. In this article, we present a model for thinking about processing as well as sample questions related to each stage and focus of the model.

\section{PARS: A MODEL FOR PROCESSING}

The components of processing group activities can be depicted in a model that offers a "road map" for processing group activities with members. The PARS model (Processing: Activity, Relationships, Self) is composed of three stages of processing, each with a possible focus on one of three specific areas. Processing includes three stages: reflecting, understanding, and applying. The three specific focus areas are: activity, relationships, and self. The PARS model provides structure for thinking about and intervening with groups to more effectively facilitate the learning process for members (see Figure 1). Once again, however, the model assumes that group leaders have a prerequisite understanding of group dynamics to be able to use the model to develop interventions for the group.

\section{Stages of Processing}

Reflecting, the first stage, simply allows the group to retrace the steps of a particular activity. This stage answers the question, "What did we do?" Following completion of an activity, it is important that group members have the opportunity to describe step-by-step the actions taken by the group. Miller (1995) suggested that it is during this stage that group

\begin{tabular}{|l|c|c|c|}
\hline & Activity & Relationships & Self \\
\hline Reflecting & Reflecting-Activity & Reflecting-Relationships & Reflecting-Self \\
\hline Understanding & Understanding-Activity & Understanding-Relationships & Understanding-Self \\
\hline Applying & Applying-Activity & Applying-Relationships & Applying-Self \\
\hline
\end{tabular}


members will share their perceptions of what took place, come to an agreement about what happened, and begin to raise some issues that may have developed as a result of the experience. This stage is normally nonthreatening to group members because the information shared is not personal in nature. Thus, this initial reflecting on the activity fosters the development of an environment in which members feel secure in sharing and opens the door to subsequent stages, in which more sensitive information may be revealed.

Reflecting allows participants the opportunity to recreate the experience by describing actions the group went through to complete the exercise. This helps group members focus their attention on what actually occurred during the activity and gives each member an opportunity to reflect on the experience. Although members all participated in the same activity, the facilitator must recognize that each individual member experiences the activity differently and has a unique perspective on the actions of the group. During this stage, those perceptions can be exposed, examined, and explored. Sharing impressions and observations of individual group members offers the group a chance to learn and discuss the various points of view, learning more about themselves and how they interact with one another in the process.

Understanding, the second stage in the PARS model, refers to the process of having participants reflect on what occurred with the group during the exercise. In this stage, the group leader helps members gain insight into group processes that took place during the exercise. Developing understanding here involves having participants share their reactions to and observations about the various interactions that occurred as part of the activity. Typically, for example, group members are asked to reflect on and discuss how group members interacted with one another. Miller (1995) stated that, during this stage, participants examine cause-and-effect relations of what was learned during the first stage. Thus, in this second stage, the primary task for group members is to identify, investigate, and analyze group processes that took place during the exercise. Sarason and Potter (as cited in Johnson et al., 1990) concluded in their study that the more people are aware of what they are experiencing, the more aware they will be of their own role in determining their success. Through the self-examination process in the Understanding stage, the group learns more about itself as a whole at the same time that members strive to reach their individual goals.

In the Understanding stage, the group leader moves the group toward a better understanding of how the group worked together as a whole. Group leaders must keep in mind the costs and rewards that are inherent in this stage. The cost to participants is that understanding requires a risk in the form of greater self-disclosure, something that can be threatening to some participants. Although in the Reflection stage members simply stated what occurred during the exercise (i.e., "We did this ... and then we did this"), in this second stage members are encouraged to discuss specific interactions and offer observations, explanations, and interpretations about these interactions (i.e., "He helped me because I was having trouble, and it made me feel like an important part of the group"). During this stage, the group should make progress in the areas of developing trust and respect. Feeling comfortable enough to share one's views with others is important in this process, and learning to appreciate the views of other participants is a step toward gaining respect for other group members.

The third stage of the PARS model is Applying. During this stage, group members are challenged and helped to apply to their relationships and activities outside the group what they have learned through the experience in the group. This stage is critical for the success of the group process because it is during this time that the relevance of the activity is examined. Each member may come from a different background, and in this stage each individual is helped to learn how to apply the information from the previous two stages in his or her daily life away from the group. In this stage, it is important that the leader have strong facilitation skills as well as some knowledge about each participant's regular environment. Having this knowledge will enable the facilitator to pose relevant questions that are appropriate for each group member. Such questions encourage members to identify what they have learned during the activity and consider how they can apply this new knowledge in their daily lives. For example, if the group has worked on problem- solving techniques, members might learn how to resolve disagreements peacefully within the group and therefore better understand how to solve such disputes in their everyday lives. An example of a question asked here might be, "What did you learn from this experience 
that you can relate to your own life?" Applying questions help group members realize the impact of the experience, because it is what they take back to their personal lives that can make a difference.

\section{Focus of Processing}

In addition to the three stages, the process model includes three areas of focus for the processing experience (the ARS in the PARS model): Activity, Relationships, and Self. In each of these focus areas, intentional questions may be used to enhance group discussions while helping members learn more about themselves and others and how the various activities can benefit them. Activity focus directs attention to the activity or event experienced, emphasizing the "facts" of what happened. Relationships focus asks participants to consider "hew" things occurred and to reflect on the interactions that occurred related to the event or activity. Finally, Self focus involves having participants examine closely their own roles and behaviors that were part of the group experience and the effects of that experience on them personally.

Activity questions help group members investigate specific situations that resulted from an activity. So, for example, questions here would relate directly to a trust fall experience (where individuals fall backward from a designated height and group members have responsibility for catching them). The facilitator might ask, "What was the most difficult part of completing this activity?" This enables each member to share what he or she found to be the most difficult part of the exercise, thereby creating more areas for discussion. One person might reply, "Falling backwards, because I didn't know for sure that I would be caught," which implies the issue of trust as a factor, whereas another individual could say, "Catching people, because I did not want to let anybody get hurt," which could lead to a discussion about issues of caring for others. The facilitator's responsibility is to attend closely to members' responses and lead the group into appropriate discussions that focus on areas of interest.

Relationship questions deal with interactions that have occurred among group members. These questions seek to help the group learn about ways they deal with each other and, through these discussions, bring them closer together as a unit. Staying with the example of completing the trust fall, the group leader might ask, "What did we do during this activity to help each other?" or "Who emerged as a leader during this exercise?" During this stage, participants are helped to examine the dynamics occurring in their particular group. For example, the group might be having problems helping each other during the activities and that too becomes an area for discussion. The facilitator must be able to recognize in this stage the direction that would be most beneficial for the group to discuss. For example, if individuals reveal issues relating to their inability to trust other group members or the ineffectiveness of the team, it is important that the leader not ignore these topics, and be able to lead the group to investigate the issues further. It is crucial to remember that if someone mentioned it, then a topic is likely to be of importance to the group.

Questions about Self are equally important for the group process. These questions encourage participants to think more about their own role in the group or how an activity affects them individually. Although group process is created to benefit the group as a whole, gaining insight into the effects of activities on members as individuals will help them experience a type of personal reflection and growth. An example of a Self question could be, "What did you learn about yourself as you went through this activity?" or "What role do you believe you played in the experience of the group?" Learning how the activity affected individual members can help them make the transition from the in-group experience back into their lives outside the group. Helping each member gain greater understanding of his or her role in the group will benefit each participant and the group as a whole.

\section{APPLICATION OF THE PARS MODEL: AN EXAMPLE}

The PARS model was created as a guide to help group leaders more effectively process with their groups. The model is represented in Figure 1. The three stages of the processing process (Reflecting, Understanding, and Applying) are listed on the left of the grid; focus areas (Activity, Relationships, Self) are listed across the top of the model. Suggested questions for each stage/focus combination are listed in the Appendix. To illustrate how and when these questions can be implemented, we will use as an example a trust fall exercise. 
An effective starting point for facilitators is the top-left grid, the Reflecting-Activity block in Figure 1. The Processing Model should be read from the left first, and the top second. For example, the top-left block is known as the Reflecting-Activity block, suggesting that stage is determined first and focus areas second. The model is separated into the three stages, and each stage is divided into three areas of focus. For purposes of this article, we will examine the various grids as if a group had completed the trust fall activity.

The Reflecting stage is the first to be explored in the model. The first grid in this stage is Reflecting-Activity. This is a natural starting point for processing. In this grid, questions should be asked regarding the details of exactly what happened during the activity. An example of a lead-off question would be, "What did we do during this activity?" Participants reflect on their individual perceptions of what occurred (e.g., "We set ourselves firmly in a standing position with arms extended and prepared to catch our partner"). Because group members experienced the activity differently, sharing these perceptions allows the group to gain some insight into the perspectives of other group members. By listening to members' discussion, the facilitator should determine what group members feel is important to the growth of the group, and then lead the discussion in that direction.

The second grid of the Reflecting stage is the Reflecting-Relationships block. It is here that the group begins to share perceptions as to what took place between and among group members themselves during the exercise. A question asked here might be, "How well did we work together to accomplish our goal?" During this section of the processing, the facilitator becomes aware of how the group is getting along by gaining insight into how the individuals feel the group as a whole worked together and how they related to each other during the exercise. Examining this issue will add to the discussion in the next stage.

After investigating the group relationship, it is crucial to examine also the Reflecting-Self block. During this segment, group members have the opportunity to reflect on their own participation in the group process. Individuals should think about their own roles in the activity and what part they played in the total group. A question to foster this type of thinking would be "What role did you as an individual member of the group play in this activity?" Discussion generated here should alert the facilitator to any problems or feelings of exclusion that may be present among some group members. As issues become known, the group leader should allow participants time to discuss and begin to work through them.

In the Understanding stage, group members begin to understand the purpose for some of the exercises and are able to make sense of what they have experienced during the previous activity. The first focus block in this stage is that of Understanding-Activity. Here, participants are asked to discuss what they believe to be the purpose of engaging in the specified activities. For example, if participants had engaged in the trust fall, a question used here might be "What purpose is there for participating in the trust fall?" and "How will that benefit our group members?" This line of questioning might lead to answers such as "It helps us begin to develop trust for each other" or "We learn to depend on other people." In this section, group members have an opportunity to discuss what purpose the activities have for them as a group. Without this type of understanding, the members might not gain anything from the experience.

After understanding the reasoning behind some of the activities, the facilitator moves to UnderstandingRelationships on the grid. Here, group members discuss how their group is working and what this means to their success as a group. For example, the facilitator might ask, "How well did we work as a group on that last activity?" and "What are our strengths and weaknesses as a group?" Creating an atmosphere for this type of discussion can benefit members in many ways. They may feel more comfortable in the group environment as well as develop trust for the leader and other group members.

In Understanding-Self, the group leader allows members the opportunity to gain insight into how they fit into the group. A question here might be "What role did you play in either helping or hindering the group, and what role would you like to play in future activities?" This allows individuals the chance to visualize how they would 
like to see themselves in the group process and opens the door for discussions as to how to meet those expectations. This section of the PARS model seeks to give each member an understanding of their importance to the group. Each member serves a purpose in the group, but unless individual members realize this, they may cheat themselves out of claiming their importance in the group.

Focus questions for the Applying stage pick up where the Understanding questions leave off. During ApplyingActivity, the leader asks group members to relate the challenges of the experience back to their real lives. For example, after the group has completed the trust fall, an appropriate question would be "When in your everyday lives can you think of a time when you would need to rely on others to help you?" This helps members realize the implications of the activity for their personal lives.

The same idea is related to. the Applying-Relationships section. Here, group members understand how to take what they have learned from the exercise and implement those ideas back into the "real world." The group leader might ask, "What did our group do well in dealing with each other that could benefit the individual members of our group back in school?" A similar line of questioning would be in Applying-Self, where the leader encourages individual members to focus on what they have learned about themselves during the entire group process. A question to be addressed to the group during this section would be "What have you learned about yourself from this activity that you perhaps did not know before?" This promotes self-awareness, which opens the door for personal growth to occur.

In this article, we have presented the PARS model as a tool to help beginning group leaders learn to move group members more effectively through processing events and activities in groups. The model provides a framework, or map, for group leaders to more intentionally and systematically process group events and experiences.

However, it is equally important that group leaders learn how and when to move from one stage-focus of the PARS model to another. Although discussion of this critical aspect of processing is beyond the scope of this article, learning how and when to intervene would include considerations such as: timing, member readiness, stage of individual members' development, stage of group development, levels of trust and support in the group, and individual and group goals.

\section{CONCLUSION}

The PARS model offers beginning group leaders a conceptual framework that provides some direction and structure to processing exercises and experiences in groups. However, it is important to remember that this is simply a model for the process, and that effective facilitators take their cues from the group itself. For example, if the group leader begins processing what occurred by asking Reflecting-Activity questions, and the group begins to discuss questions typically asked in the Understanding-Relationships section, the group leader should follow the conversation. Although the facilitator should try to keep some order in the group, it is the group members' agenda that is most important. Therefore, if members discuss a particular topic, it is probably important to the group process and may suggest the need to move the processing into a different stage-focus in the model. 


\section{APPENDIX \\ PARS Processing Questions}

\section{Reflecting-Activity}

1. What did we do during this activity?

2. What was the hardest part of this challenge?

3 . What was the easiest part of this challenge?

\section{Reflecting-Relationships}

1. How did we act toward each other during this experience?

2. What kinds of things did we say to each other while we were doing the activity?

3. How did we as a group work through the challenge?

4. What did we do during this activity to help each other?

5 . Who emerged as a leader during this exercise?

\section{Reflecting-Self}

1. How did you as an individual participate in this challenge?

2. Were you a help or a hindrance to the success of our group during this exercise?

3. What role did you assume in the group during this challenge?

4. What did you do during this activity that you are most proud of?

5. What did you do during this activity that you are most disappointed in?

\section{Understanding-Activity}

1. Thinking about how we performed on the last challenge, what does this say about our group?

2. What did we learn about our group on the previous activity that we did not know before?

3. After observing how we performed on the last challenge, what do you believe are the strengths and weaknesses of our group?

4. What is the purpose of our participating in this activity?

5 . How will this challenge benefit our group members?

\section{Understanding-Relationships}

1. Considering what we said earlier about our group, what does this say about our ability to work with others in the group?

2. How well does our group work together?

3. How efficient are we as a group at solving problems?

4. How well does our group work together at accomplishing a common goal?

5. Is our group able to put aside differences to succeed?

6. How well is our group able to listen to one another and share ideas?

7. How will working together benefit our group?

\section{Understanding-Self}

1. Considering what you said earlier about your participation in the group activity, what have you learned about yourself that you perhaps did not know before?

2. Viewing how you performed during this challenge, what does this say about your investment in this group?

3. Do you feel that you acted in a manner that demonstrates how important the success of this is to you?

4. How does participation in these activities benefit you as an individual?

\section{Applying-Activity}

1. What have we learned from participating in this particular challenge that will benefit us in our daily lives?

2. What skills did we use during this activity that we may use back in the "real world?" 


\section{Applying-Relationships}

1. What did our group do well in dealing with each other that could benefit the individual members of our group back in school/work/home?

2. What skills did we use with each other that will help us with other people back in our daily environments?

3. What have we learned about working with others that will help us in other situations?

\section{Applying-Self}

1. What have we learned about ourselves that may affect how we handle other situations in the future?

2. What will you do differently as individuals back in your daily routines that will be a result of what you have learned here?

\section{REFERENCES}

Corey, M. S., \& Corey, G. (1997). Groups: Process and practice ${ }^{\left(5 d^{\prime}\right.}$ Pacific Grave, CA:

Brooks/Cole.

Dishon, D., \& O'Leary, P. (1984).A guidebook for cooperative learning. Holmes Beach, FL: Learning Publications. Dutton, J. E., \& Stumpf, S. A. (1991). Using behavioral simulations to study strategic processes. Simulation \& Gaming, 22, 149-173.

Egan, G. (1994). The skilled helper: Aproblem-management approach to helping (5th ed.). Pacific Grove, CA: Brooks/Cole.

Ivey, A. E. (1994). Intentional interviewing and counseling: Facilitating client development in a multicultural society (3rd ed.). Pacific Grove, CA: Brooks/Cole.

Jacobs, E., Harvill, R., \& Masson, R. (1988). Group counseling: Strategies and skills. Pacific Grove, CA: Brooks/Cole.

Johnson, D. W., \& Johnson, R. T. (1987). Learning together and alone: Cooperative, competi-

tive, and individualistic learning (2nd ed.). Englewood Cliffs, NJ: Prentice Hall.

Johnson, D. W., Johnson, R. T \& Holubec, E. (1986). Circles of learning: Cooperation in the

classroom (Rev. ed.). Edina, MN: Interaction.

Johnson, D. W., Johnson, R. T., Stanne, M. B., \& Garibaldi, A. (1990). Impact of group proc-

essing on achievement in cooperative groups. Journal of Social Psychology, 130,507-516. Kees, N. L., \& Jacobs, E. (1990). Conducting more effective groups: How to select and pro-

cess group exercises. Journal for Specialists in Group Work, 15, 21-29.

Miller, D. (1995, May/June). Group facilitating. Camping, 67(5), 28-32.

Thatcher, D. C. (1990). Promoting learning through games and simulations. Simulation \& Gaming, 21, 262-273.

Yager, S., Johnson, R. T., Johnson, D. W., \& Snider, B. (1986). The impact of group processing on achievement in cooperative learning groups. Journal of Social Psychology, 126, 389397. 